\title{
Dois atlas para a América Latina
}

Kelvin Falcão Klein

UEPG

\begin{abstract}
Resumo
O objetivo deste artigo é resgatar a ensaística breve do poeta e crítico argentino Héctor Ciocchini. Ênfase especial é dada a sua produção da década de 1960, período que marca a estada de Ciocchini no Warburg Institute, em Londres. Discutindo a obra do escritor e aviador francês Antoine de Saint-Exupéry (e sua passagem pelo continente sul-americano), Ciocchini propõe uma visão do território latino-americano a partir de uma perspectiva aérea que borra as fronteiras, daí a metáfora crítica organizadora do atlas, e a partir de uma perspectiva poética que borra as temporalidades. Finalmente, este artigo procura estabelecer uma ponte com o pensamento contemporâneo a partir da leitura de Atlas portátil de América Latina, livro publicado em 2012 por Graciela Speranza, problematizando-o a partir de três pontos: a utilização latino-americana do nome de Aby Warburg; a elisão do nome de Héctor Ciocchini; e a proliferação teórica da ideia de atlas.

Palavras-chave: Héctor Ciocchini; Graciela Speranza; Atlas; Montagem; América Latina.
\end{abstract}

\section{Riassunto}

Lo scopo di questo articolo è quello di riscattare la opera saggistica dello poeta e critico argentino Hector Ciocchini. Particolare enfasi è data alla produzione del 1960, periodo che segna il soggiorno di Ciocchini presso il Warburg Institute di Londra. Discutendo il lavoro dello scrittore e aviatore francese Antoine de Saint-Exupéry (e il suo passaggio attraverso il continente sudamericano), Ciocchini propone una visione del territorio latino-americano da una prospettiva aerea che sfuma i confini, quindi la metafora organizzatora critica del'atlante, e da una prospettiva poetica che confonde le temporalità. Infine, questo articolo cerca di stabilire un ponte con la lettura contemporanea dal Atlas portátil de América Latina, libro pubblicato nel 2012 da Graciela Speranza, discutendo tre punti: l'uso latino-americano del nome di Aby Warburg; l'elisione del nome di Héctor Ciocchini; e la proliferazione dell'idea teorica di atlante.

Parole chiavi: Héctor Ciocchini; Graciela Speranza; Atlante; Montaggio; América Latina. 
1. BURUCÚA, José Emilio.

Historia, arte, cultura, 2007, p. 104.
Héctor Eduardo Ciocchini (La Plata, 1922 - Buenos Aires, 2005) foi um dos principais nomes por trás do florescimento do Instituto de Humanidades da Universidad Nacional del Sur, em Bahía Blanca, ao longo da década de 1950 e 1960. Com o incentivo do professor de filosofia Francisco Maffei e sobretudo com o apoio de Vicente Fatone, Ciocchini fez parte de um grupo de professores que incluía, entre outros, o tradutor de Platão Antonio Camarero, o heideggeriano de primeira hora Carlos Astrada, Rodolfo Agoglia, Jaime Rest e Antonio Austral. Com sua atividade dupla de poeta e professor, Ciocchini incentivava um ambiente que poderíamos chamar, talvez anacronicamente, de "transdisciplinar", com a articulação permanente de textos e imagens de variadas latitudes e épocas. Havia uma publicação que organizava essa variabilidade, os "Cuadernos del Sur", ou ainda "Los trabajos de Anfión" para os frequentadores, espaço de circulação teórica e de colocação em prática das aulas dadas no Instituto de Humanidades.

Em seu Historia, arte, cultura: de Aby Warburg a Carlo Ginzburg, de 2003, José Emilio Burucúa fala do Instituto: “é quase certo que o modelo imaginado e aplicado nesse lugar foi o Warburg Institute de Londres", pois "não apenas Ciocchini frequentou a biblioteca de Woburn Square na qualidade de investigador visitante em inícios dos anos sessenta" e, entre parêntesis, Burucúa acrescenta que Ciocchini "voltaria, mais tarde, em 1976, exilado pela tirania militar depois do 'desaparecimento' e assassinato que esse regime perpetrou contra sua filha María Clara, uma adolescente de 16 anos”, e retoma: "não apenas portanto pela familiaridade de nosso Héctor com o lugar cuja irradiação estudamos, mas também que o interesse de Aby Warburg pela Nachleben der Antike já havia atraído a atenção de três intelectuais argentinos ativos nos anos quarenta e cinquenta", intelectuais "que Ciocchini chamou de seus mestres”, a saber, o já citado Fatone, Arturo Marasso e Ezequiel Martínez Estrada ${ }^{1}$.

Já de saída, fica estabelecido um contexto de troca cultural marcado não pela narrativa hegemônica de um modo de conceber seja a arte, a cultura ou o ensino, mas um sistema descentralizado de utilização das referências - sejam elas teóricas ou da ordem da convivência. Trata-se, portanto, de estabelecer desde já a percepção de um contexto de ensino e pesquisa que se vale da montagem de fragmentos provenientes de tempos e espaços heterogêneos. Para melhor exemplificar esse contexto, proponho o resgate de um ensaio que Ciocchini publica em 1966, no âmbito do Instituto de Humanidades da Universidad Nacional del Sur, especificamente no âmbito dos "Cuadernos del Sur". O ensaio, "Hacia un humanismo contemporáneo, Saint-Exupéry, René Char”, marca ao menos dois eventos: o retorno do pesquisador argentino a Bahía Blanca depois de seu 
período como visitante no Instituto Warburg e, finalmente, a cristalização de uma série de apontamentos (realizados nesse período anterior que se encerra) que Ciocchini prepara na década de 1960 em torno às obras de Antoine de Saint-Exupéry e René Char².

É precisamente desse ensaio que Burucúa, em outra ocasião - sua conferência "Repercussões de Aby Warburg na América Latina" -, retira um trecho que, para ele, permite "compreender melhor aquela primeira tentativa de generalização das ideias que Warburg tinha formulado somente a partir de suas investigações sobre a arte do Renascimento". Aproveito a tradução ao português de Alberto Martín Chillón do trecho de Ciocchini citado por Burucúa:

Encontrar os mitos que definem o destino do homem do presente parece ser a obra desses solitários [Saint-Exupéry e Char]. Neles toda filiação literária, toda categorização resulta mesquinha. Têm conseguido aprisionar um sopro de vida e curar uma ferida que ainda nos dói. Essencialmente, ainda que sejam escritores, são escritores a seu pesar, e justamente essa característica define seu crescente classicismo; e digo crescente no grau em que o traço distintivo do classicismo é formar e ser motor da ação em novos homens. Dois homens de ação, que por si mesmos são um mito que incentiva e inspira o homem contemporâneo. $\mathrm{O}$ espírito do dever que vai além do indivíduo, da sua morte individual, e trata de eternizar na vontade e na criação sua precária existência, no caso de Saint-Exupéry. A tenaz vontade de transformação pela poesia que volta a recolher as profundas vertentes do conhecimento de Hölderlin e Nietzsche e se projeta na cristalina e afilada escuridão de uma Grécia ressuscitada na palavra da beleza e da dor, em René Char. ${ }^{3}$

O longo ensaio de Ciocchini se organiza a partir da montagem de fragmentos, de breves seções que tocam pontos diversos das poéticas tanto de Saint-Exupéry quanto de René Char. Mais do que isso, cada seção ensaia também uma dinâmica diversa e uma intensificação própria da articulação entre os dois autores e a articulação mais ampla que propõe Ciocchini entre a literatura contemporânea e os motivos clássicos que sobrevivem. São exatamente catorze fragmentos presentes na composição do ensaio, intitulados, respectivamente, "O hiato", "O desejo de comunicação", "O poema do esforço", "O ser itinerante", "Caminhante e alpinista”, "Em direção a um tipo de homem”, "A cidade pessoal”, "Teoria da linguagem e arte do governo", "O mito humano e as leis da vida", "A vida anterior", "Saint-Exupéry e a Cabala", "Linguagem", "Estilo" e, finalmente, "O geômetra". "Mais do que colocar-me como crítico de Saint-Exupéry ou René Char”, escreve Ciocchini na
2. Na edição de número 22 da revista L'arc, de 1963, Héctor Ciocchini publica em francês um texto intitulado "La parole habitable", dedicado ao poeta René Char, que era o foco do dossiê temático dessa edição da revista (que contou também com um texto de Maurice Blanchot, "René Char et la pensée du neutre"). Os dossiês temáticos eram comuns em L'arc (sobre Queneau ( $\mathrm{n}^{\circ} 28$ ), sobre Bataille (32), Fellini (45), Duchamp (59), Cortázar (80), Henry Miller (97)), cujo primeiro número saiu em janeiro de 1958 e o centésimo (e último) em janeiro de 1986, editada por Stephane Cordier em Aix-en-Provence (6, rue Ancienne Madeleine).

Trata-se, portanto, de uma produção de Ciocchini do período em que estava atuando no Instituto Warburg. Um trabalho sobre as relações entre o pesquisador argentino e o poeta René Char ainda está por ser feito (os dois se tornaram amigos a partir de uma intensa troca de cartas justamente nos inícios da década de 1960, um contato que só foi interrompido com a morte de Char, em 1988; trocavam poemas, recortes de jornal, revistas, indicações bibliográficas).

3. BURUCÚA, José Emilio. "Repercussões de Aby Warburg na América Latina". Revista Concinnitas, 2012, s/p. 
4. CIOCCHINI, Héctor.

"Hacia un humanismo contemporáneo, Saint-Exupéry, René Char". El sendero y los días, 1973, p. 8. Tradução minha, como em todas as citações de Ciocchini daqui por diante.

5. Ibidem, p. 37.

6. Ibidem, p. 39. introdução ao ensaio, "pretendi aproximar, a partir de uma ordenação e de rubricas, a obra desses autores a uma juventude que vejo necessitar a organização de sua angústia", e "minha tarefa”, continua Ciocchini, "pode ter sido encontrar as 'linhas de força' que na obra desses autores foram eminentemente úteis para minha experiência pessoal, pensando que podem ter uma refração mais funda e saudável naqueles que abrem as páginas deste livro"4.

O procedimento de escrita que Ciocchini professa aqui se mostra, também, como um procedimento de ensino - sua experiência como leitor dos escritores em questão deve servir para possibilitar o caminho de outras experiências, "aqueles que abrem as páginas deste livro”. Aí retorna, portanto, a ideia da "brevidade" ensaística, pensada também a partir da forma, sem dúvida (a forma do ensaio como colagem e montagem de fragmentos independentemente intitulados, por exemplo), mas também uma "brevidade" que se configura a partir dessa incerteza da recepção, uma incerteza que, no entanto, e paradoxalmente, se apresenta também esperançosa. "Esperançosa" no sentido de uma emergência contingente, no sentido de uma "semente", espécie de termo-chave, de metáfora que surge frequentemente na argumentação de Ciocchini no ensaio em questão: “A apreciação geográfica surge naturalmente à substância interior do ser humano. Na vida precária, pronta a ser varrida em um instante, uma grandeza interior brota" ${ }^{\circ} \mathrm{e}$ "a árvore se comporta, sem saber, como o homem verdadeiro, o peregrino, que generosamente dá tudo de si e se alça na permanência"'.

O ensaio de Ciocchini vale-se tanto da forma quanto do conteúdo para passar uma mensagem de permanência heterogênea dos tempos, uma permanência que pode ser acessada somente a partir do trabalho sério e continuado de leitura algo que envolve a percepção de uma "angústia", a angústia da geração vindoura para Ciocchini (algo que ganhará repercussões trágicas alguns anos depois, como lembrou Burucúa no comentário sobre María Clara, a filha de Ciocchini assassinada pela ditadura). Nessa perspectiva, temos um contexto complexo que articula variados níveis de experiência, que tocam tanto a vivência particular da cultura (a ida do ensaísta ao Instituto Warburg, sua preparação humanista rigorosa) quanto o cotidiano social que marca a passagem de um regime democrático para um regime ditatorial (o espaço de vanguarda construído no Instituto de Humanidades, em seguida dissolvido; a percepção de Ciocchini de que suas ideias e sua experiência de pesquisador e leitor poderiam servir, eventualmente, para a reconstituição de uma postura perdida diante do conhecimento e da cultura). 
O modelo de heterogeneidade, que serviu tanto para Ciocchini como também para a argumentação deste meu ensaio, será o do atlas de Aby Warburg, compreendido, segundo a definição de Georges Didi-Huberman, como uma sorte de "sismografia de tempos móveis"7. O atlas se apresenta, portanto, como registro provisório de uma série de imagens, tanto visuais quanto históricas, e que problematizam esse pertencimento duplo a cada vez que são requisitadas. O trabalho crítico de Warburg toma como pressuposto, e assim o fará também Ciocchini, a heterogeneidade inerente aos fragmentos presentes no arquivo. Não há qualquer pretensão de originalidade em qualquer dos fragmentos compostos no Atlas, o que desviaria o esforço hermenêutico em direção a uma crítica genética ou à formação de um repertório hierarquizado de repetições - avatares de um projeto essencialista e, consequentemente, redutor ${ }^{8}$.

Monta-se um mosaico de referências a partir desses fragmentos estabelecidos por Ciocchini em seu ensaio, um mosaico que articula tanto a teoria de matriz warbuguiana (a sobrevivência da Antiguidade, a contínua atenção às sobrevivências de temporalidades e geografias soterradas pelo discurso hegemônico) quanto a apropriação latino-americana dessa mesma matriz (o "humanismo contemporâneo" de Ciocchini a ser apropriado como uma tática de permanência desse legado crítico de resgate das heterogeneidades históricas, ou seja, a própria disposição dos fragmentos ensaísticos de Ciocchini como um espelhamento do contexto de perda que em breve iria se instalar na América Latina). Proponho uma leitura do ensaísmo breve de Ciocchini como uma estratégia textual carregada de complexas intenções - aquelas que remetem a uma operacionalização das teorias warbuguianas (os motivos arcaicos nos textos de Saint-Exupéry e René Char, por exemplo) e a uma operacionalização da reivindicação política no âmbito do ensino e da aprendizagem.

Em Historia, arte, cultura, Burucúa comenta a aproximação de Ciocchini do Instituto Warburg a partir de uma noção bastante materialista da sobrevivência dos artefatos culturais. O que teria aproximado o ensaísta argentino da então diretora do Instituto, Frances Yates, seria a colocação de uma mesma pergunta: "Como é possível que essas criações, as mais frágeis do espírito humano, confiadas à conservação em suportes o papiro, o pergaminho, o papel - que um pequeno fogo e um pouco de água podem destruir para sempre”, como é possível, continua Burucúa, "que permaneçam e se transmitam através da história, para além das catástrofes, das quedas dos impérios e das civilizações?" . A resposta está "em encontrar os itinerários dialógicos, os diretos, com a presença física das pessoas, e os indiretos, por cima do tempo e do espaço, que se realizam através da escritura" ${ }^{10}$. Ao mesmo tempo em que

\section{DIDI-HUBERMAN,} Georges. "Sismographie des temps mouvants", 2002, p. 117125.

8. KLEIN, Kelvin Falcão. "O Atlas e as Passagens: rarefação do eu diante do arquivo". Revista Confluenre, 2013, p. 18.

9. BURUCÚA. Historia, arte, cultura, 2007, p, 105. Tradução minha, como todas as citações de Burucúa daqui por diante. 10. Ibidem, p. 106. 
11. Cf. AGAMBEN, Giorgio.

"Aby Warburg e la scienza senza nome". La potenza del pensiero: saggi e conferenze, 2005, p. 123146.

12. BURUCÚA. Historia, arte, cultura, 2007, p. 107. O tema do voo noturno ocupa uma vasta bibliografia, especialmente no que diz respeito aos estudos sobre a demonologia e a condenação da bruxaria na Idade Média (como é o caso de GINZBURG, Carlo. História noturna: decifrando o sabá, 1991). $\mathrm{Na}$ inflexão dada por Ciocchini, que explora o voo a partir da relação do humano com a técnica, da fusão do corpo (do aviador, Saint-Exupéry) com a máquina, o tema ganha repercussão na própria obra de Aby Warburg - ver "Aeronave e submergível no imaginário medieval", de 1913 (A renovação da Antiguidade pagã, 2013, p. 313-321). Ou ainda a contribuição de Leo Popper, que se vincula à iconologia de matriz warbuguiana, "Per un'estetica dell'aeroplano" (Cf. POPPER, Leo. Scritti di estetica, 1997, p. 63-66). leva a uma consideração quase que pessimista da permanência da arte e da cultura - a menção à fragilidade dos suportes -, esse questionamento compartilhado por Yates e por Ciocchini revela igualmente uma confiança no mistério da própria permanência. Finalmente, por trás dessa primeira confiança, reside a consciência de que os procedimentos de análise e leitura são fortalecidos precisamente no confronto com a fragilidade dessa permanência - em outras palavras, é a consciência da fragilidade da permanência dos artefatos que fortalece a ciência que deles se ocupa (a "ciência sem nome" de que fala Giorgio Agamben a respeito desse mesmo questionamento de Yates e Ciocchini $\left.{ }^{11}\right)$.

Ainda segundo Burucúa, "a maior originalidade do trabalho de Ciocchini como scholar se situa na extrapolação que fez em direção à arte contemporânea da busca pelo Nachleben e pela conformação de uma mitologia moderna". "Magritte, Valéry, Saint-Exupéry e René Char foram”, continua Burucúa, "em tal sentido, os autores principais estudados em seus ensaios”. De Saint-Exupéry, que nos interessa especialmente aqui, "Ciocchini destaca sua elaboração do mito do 'voo noturno' no qual o avião frágil faz as vezes do pássaro veloz da noite que, na mitologia antiga, simboliza a fugacidade da vida e o mistério nos extremos, passado e futuro, do tempo"12. A ideia exposta por Burucúa de uma "mitologia moderna" se harmoniza com aquilo que Ciocchini já expõe no título de seu ensaio, "por um humanismo contemporâneo". O que está em jogo entre essa atualização da mitologia e essa revitalização do humanismo é precisamente a leitura do contemporâneo a partir de um instrumental arcaico - um arcaico que vem não apenas de Warburg, mas de Warburg resgatando o Renascimento e este, finalmente, resgatando a Antiguidade pagã. Desse mise-en-abyme tão característico, e restringindo o olhar à obra de Saint-Exupéry, Ciocchini extrai uma imagem carregada de Nachleben - de "vida póstuma", de "sobrevivência" do arcaico -, uma imagem que é ao mesmo tempo índice do desenvolvimento econômico e científico e índice de uma das mais primitivas fantasias do homem, o desejo de voar.

É a partir da utilização efetiva do avião que Saint-Exupéry extrai sua criação ficcional, e, nesse processo, argumenta Ciocchini, atualiza a mitologia clássica do voo noturno em uma mitologia moderna que mescla o desejo de ascensão (o sucesso, o domínio sobre a máquina e a natureza) com o desejo de morte (a queda, o encontro fatal com a terra que é observada do alto e que parece esperar a falha do piloto). O fragmento do ensaio de Ciocchini que se ocupa de Saint-Exupéry através da imagem do avião é aquele intitulado "O desejo de comunicação", que é suplementado adiante por "O ser itinerante”. "A paixão pelo sagrado da vida, por sua matéria imperecível 
marca a obra de Saint-Exupéry”, escreve Ciocchini na primeira frase do fragmento "O desejo de comunicação", e continua: "E dentro dela um meio de penetração, um instrumento, o avião, e um objeto, a terra, marcam essa leitura que se fará através de sinais mais ou menos evidentes, de belas visões e mitos que precedem a essa comunhão e a esse conhecimento que resulta de sua experiência"13.

Para Ciocchini, essa escolha de Saint-Exupéry, ainda que indique uma contingência muito específica de sua vida, uma contingência material que o levou tanto ao avião quanto à carreira de aviador, tal escolha acarreta um radical investimento simbólico. O pacto que Saint-Exupéry estabelece com o avião é um pacto que diz respeito ao contato do homem com a técnica na modernidade (na era do capitalismo tardio, por assim dizer), mas também, e sobretudo, um pacto do homem com aquilo que o ultrapassa em termos simbólicos - a dimensão histórica do desejo e da escolha. Ciocchini articula, a partir dessa perspectiva dúplice do pacto, uma dialética suplementar, aquela que relaciona o avião e a terra, um "instrumento" e seu "objeto", ambos ligados naquilo que ele denomina uma "comunhão". Há um conhecimento - poético e mitológico - que Saint-Exupéry alcança a partir do exercício dessa comunhão, argumenta Ciocchini. Esse conhecimento alcançado pelo artista é desvelado pouco a pouco em sua obra a partir de "sinais mais ou menos evidentes", como coloca Ciocchini, "belas visões e mitos” que funcionam como preparação para essa comunhão, "visões e mitos" que Saint-Exupéry tem acesso a partir da mediação de seu instrumento, o avião.

À visão da "vida latente nos lugares desertos", escreve Ciocchini, "segue o conhecimento que se traduz como desejo de comunicação, como desejo de alcançar um infinito que participa da sagrada vibração da vida". "A solidão do piloto noturno", continua ele, "o mistério dessas consciências solitárias, se une a cada um dos homens que habitam esse rosto deserto da planície ou das colinas e que só se manifesta em uma pequena luz"14. Ao mesmo tempo em que marca a ligação entre o arcaico, com o motivo do "voo noturno", e o moderno, com o motivo do avanço da técnica, o avião também marca a ligação entre o individual e o coletivo, a articulação entre "a solidão do piloto noturno", aquele que vê, e "cada um dos homens que habitam esse rosto deserto da planície”, aqueles que são vistos à distância. Aí, portanto, a ligação complexa entre tempo e espaço, o arco simbólico que leva da reflexão sobre o tempo (o avião no presente, o voo noturno no passado) à reflexão sobre o espaço (a visão do piloto noturno; o avião visto de baixo pela planície e as colinas, ou seja, mais um desdobramento da dialética entre "instrumento-avião" e "objeto-terra" exposta anteriormente por Ciocchini).
13. CIOCCHINI. El sendero y los dias, 1973, p. 24.

14. Ibidem, p. 25. 

latino-americana, problematizando-a a partir desse contexto interpretativo que leva em conta elementos poéticos, mitológicos, estéticos e políticos. Ciocchini começa comentando o prefácio de Terra de homens (Terre des hommes, publicado originalmente em 1939), no qual Saint-Exupéry reflete sobre a terra como "obstáculo" e sobre o homem que só se descobre quando "se mede contra o obstáculo". Mas, para alcançar o obstáculo, é preciso uma "ferramenta": o camponês, com o arado, "arranca pouco a pouco alguns segredos da natureza”, e de igual maneira, o avião, "a ferramenta das linhas aéreas", em contraposição às linhas terrestres, "complica o homem com todos os velhos problemas”. Ciocchini comenta que, para Saint-Exupéry, “o ato de escrever está investido de uma tal transcendência que permite a comparação com outros fenômenos de psicologia religiosa”. E essa experiência da escritura, para Saint-Exupéry, escreve Ciocchini, "está vinculada com o sul argentino, com suas extensões mais desérticas e inóspitas, nas quais o autor encontra um sentido em sua geografia e em seus homens". Nesse mesmo prefácio a Terra de homens, "a Argentina aparece como um mito que insistentemente volta à memória", e a "solidão patagônica (...) se comunica em uma memória essencial que os faz", aos homens, "partes do mundo". "Como São Jerônimo, que descobre seu sentido e povoa sua solidão, Saint-Exupéry indaga o milagre do deserto em lugares como San Julián, Río Gallegos, Punta Arenas, descobrindo nas entranhas da seca solidão jardins e hortos ocultos ao olhar da gente, ricos de um mistério insondável" ${ }^{15}$.

Quando vista do alto, de dentro de um avião, a terra apresenta uma lógica diversa. Os limites da terra podem ser reescritos e reinterpretados pelo aviador a partir de sua percepção, daí a ideia de uma reformulação do espaço latino-americano, por parte de Saint-Exupéry, a partir da configuração de um atlas especial, um atlas poético que inaugura seus próprios marcos de localização e significação. Como o Atlas Mnemosyne de Aby Warburg, marcado pela convivência tensa e criativa de imagens provenientes de fontes, técnicas, temporalidades e geografias as mais diversas, também o atlas poético que Ciocchini reconhece em Saint-Exupéry faz do espaço latino-americano em geral, e do sul argentino em particular, um espaço de experimentação, um laboratório de articulação entre a criação estética e o pertencimento nacional. Assim como no cotidiano do Instituto de Humanidades se reconhecia a marca do Instituto londrino, e assim como no estilo e nos temas de Ciocchini se reconhecia a marca de sua filiação estrangeira, da mesma forma o olhar de Saint-Exupéry transforma essa geografia doméstica a partir de uma ressignificação poética. Da mesma forma, o olhar estrangeiro do escritor francês é reposicionado a partir do contato 
com a terra alheia, uma vez que a dialética entre instrumento e objeto (ou seja, entre avião e terra, como visto acima) repercute também na dimensão da escrita, da elaboração ficcional da vivência e da experiência (sendo esse um aspecto fundamental, que Ciocchini, como vimos, resgata em seu endereçamento do ensaio às gerações vindouras).

"Uma das engrenagens mais finas de seu estilo", continua Ciocchini sobre Saint-Exupéry, "é esse mito geográfico que se repete cada vez com maior insistência. Aos olhos do leitor moderno adquire o encanto da legenda medieval, volta a penetrar, com a nova ciência, na infinitude das substâncias na qual se reúne essa substância original sempre viva no homem"16. Aqui mais uma vez Ciocchini reforça aquilo que vê de heterogêneo no esforço poético de Saint-Exupéry, uma heterogeneidade que diz respeito tanto ao tempo (o "hoje" da visão do aviador/poeta será sempre distinto do "hoje" da terra, seu objeto, objeto de seu olhar, que responde a uma cadência diversa do tempo) quanto ao espaço (a terra que observa, o sul argentino, por exemplo, está irremediavelmente mesclada às terras que outrora observou e que servem de contraste).

Assim como cada fragmento ensaístico de Ciocchini remete à grande peça que ele organiza, nomeia e publica - sem, contudo, estabelecer uma hierarquia de sentido entre as variadas peças -, também o atlas poético de Saint-Exupéry responde ao mesmo desejo de des-hierarquização da percepção do espaço: "O ser humano que se sabe passageiro, itinerante, parece ser o único que tem o sentido de sua habitação na terra”, escreve Ciocchini na frase de abertura do fragmento "O ser itinerante", e continua: "Distância e carência outorgam sentido aos alimentos, e fazem florescer uma memória que devolve a realidade vestida de presença". "Nas extensões desertas", continua Ciocchini, "a Patagônia, o Saara, Saint-Exupéry se volta a uma memória profunda da infância”. Porque a presença do ser humano "quer indagar as extensões mais estranhas, entrar no coração do mistério, ser uma presença viva no planeta, ainda que nos rincões mais desolados; e tem o poder de levar a intimidade ao mais vasto, ao mais insensível" ${ }^{\prime 17}$.

O atlas poético de Saint-Exupéry, conforme capturado na ensaística de Héctor Ciocchini, faz da visão contemporânea da Patagônia um resgate também do Saara, do contexto colonialista francês de inícios do século XX e, consequentemente, da dimensão "profunda da infância”, como aponta Ciocchini. "O ser itinerante adquirirá na noite a visão de um planeta deserto", escreve ele, e "quanto mais distante está de toda presença humana, sua visão do homem adquirirá mais sentido. E, perdidos irremediavelmente no deserto, as leis humanas adquirirão sua formulação mais adequada"18. E mais adiante completa: "A natureza em Saint-Exupéry culmina no homem; este sempre é
16. Ibidem, p. 28.

17. Ibidem, p. 40.

18. Ibidem, p. 43. 
19. Ibidem, p. 45.

20. Em outra ocasião, tive a oportunidade de desenvolver algumas ideias a respeito desse resgate do "voo noturno" como imagem arcaica na literatura contemporânea, um tema que deverá ser resgatado futuramente levando em consideração as intuições de Ciocchini acerca da percepção que Saint-Exupéry registrou da geografia latino-americana. No texto a que me refiro, a novela Estrela distante, de Roberto Bolaño, é lida em conjunto com a conferência de W. G. Sebald sobre Guerra aérea e literatura, com a intenção de observar certas articulações entre ética e estética nas ficções que tematizam a violência no período pós-II Guerra. Cf. KLEIN, Kelvin Falcão. "Literatura e guerra aérea: poesia contemporânea em Roberto Bolaño". Revista FronteiraZ, 2011, p. 02-12. um milagre infinito desse incessante esforço por chegar à superfície de uma verdade", pois "a natureza da verdade humana é uma busca" 19 .

A "busca” em Saint-Exupéry, resgatada por Ciocchini como signo mitológico, ou seja, como indício da criação de uma "mitologia contemporânea", se refrata em duas potências: uma busca pelo arcaico, pelos tempos imemoriais que ficam acessíveis através do olhar distanciado do aviador (o tema da atualização do "voo noturno", como exposto anteriormente), e uma busca pela infância, pela sensação primordial do "estar no mundo”. Essas duas versões da busca ganham ressonância também na já mencionada dialética entre o instrumento e seu objeto, entre o avião e a terra, que coexistem a partir de um sistema tenso de relações - é da terra que sai o avião e é a ela que ele retorna, sem com isso remover a constante consciência de que a terra também puxa o avião para si. Nesse sentido, a morte, que ocorre quando a terra tem sucesso em puxar o avião para si (ou seja, o momento em que o objeto absorve o instrumento que dele se ocupa), é tanto uma reivindicação da experiência do retorno ao arcaico quanto uma lembrança enviesada desse momento primitivo da experiência, que em Saint-Exupéry é nomeado como "infância".

Podemos apontar, finalmente, para a complexa configuração desse atlas poético de Saint-Exupéry tal como dissecado por Ciocchini: ele se apresenta fragmentado em quatro compartimentos interligados, dois deles que dizem respeito à geografia particular do aviador (a união da Patagônia com o Saara, em linhas gerais), dois deles que dizem respeito à imagem particular do tempo que daí emerge (a infância como experiência primitiva do mundo e, mais profundamente, o exercício poético como acesso à consciência primitiva - ou primeva - do "estar no mundo"). Nesse ponto, Ciocchini e Saint-Exupéry se misturam na análise que estou propondo aqui, pois o procedimento de análise do ensaísta termina por espelhar os conflitos do artista, e ambos aproveitam certa faceta estrangeira (nômade ou "itinerante", para usar um termo-chave para Ciocchini) de suas experiências para plasmar uma leitura de mundo diversa. É, portanto, essa heterogeneidade que está por trás da ideia de atlas (a heterogeneidade do pesquisador latino-americano em Londres e do aviador francês no sul argentino). Além disso, tal heterogeneidade se encaminha em direção a uma dinâmica descontínua de percepção do tempo e da geografia, dinâmica essa que deve ser retida e cultivada em um exercício de contaminação também do presente e de suas linhas de força ${ }^{20}$. 
21. Como salientado no caso de Ciocchini (cujo ensaio

Um pouco desse exercício de contaminação foi esboçado por Graciela Speranza em seu livro Atlas portátil de América Latina: arte $y$ ficciones errantes, publicado originalmente em 2012. A filiação com Aby Warburg, que no caso de Ciocchini era mais velada, se escondendo nos detalhes de seu método e seus temas, agora se torna manifesta e nomeada, sobretudo através da mediação de Georges Didi-Huberman e sua exposição Atlas, como levar o mundo nas costas?, realizada no Reina Sofía em 2011 (como Speranza relata no prólogo). Não apenas a presença e o nome de Warburg se tornam mais efetivos, mas também a própria ideia de atlas, ou o atlas como uma categoria operatória. Aquilo que em Ciocchini precisava ser decifrado de sua leitura de Saint-Exupéry - o "atlas poético" que surge da visão do aviador diante do sul argentino e suas fronteiras e pontos de localização borrados -, em Speranza se torna aberto e manifesto.

Já de saída, o que se problematiza em Atlas portátil é precisamente essa visão estrangeira da América Latina, um dilema que não se resolve nem no multiculturalismo sem critério (denunciado como tática do capitalismo tardio), nem na hierarquização geopolítica conservadora. Além disso, assim como acontece com Ciocchini, a aproximação do problema se dá de forma fragmentada, como se a forma ensástica emulasse o próprio questionamento concernente às fronteiras, aos limites e aos marcos de localização. Se o ensaio de Ciocchini é feito de múltiplas entradas com títulos e temáticas diversas, que vão, pouco a pouco, coordenando Char, Saint-Exupéry e a ideia de um "humanismo contemporâneo", o ensaio de maior fôlego de Speranza é composto, também ele, por um procedimento de articulação de peças heterogêneas. Seu escopo de análise vai da literatura às artes visuais, tocando a obra de escritores como João Gilberto Noll, Mario Bellatín e Roberto Bolaño, e de artistas como Gabriel Orozco, Liliana Porter e Tomás Saraceno, e o resultado final é a junção de trabalhos, comunicações e conferências apresentados em diferentes lugares ${ }^{21}$.

No prólogo, Speranza adverte o leitor que seu projeto de um atlas da América Latina surgiu em paralelo ao surgimento da exposição de Didi-Huberman no Reina Sofía. Diante da exposição, explica Speranza, algo imediatamente lhe ocorreu: "Uma das fotos, uma paisagem desolada no deserto de Sonora ou da Patagônia, me distrai e me deixa pensando no 'mundo visível' de Didi-Huberman. Se não me engano e tirando Borges", que foi utilizado por Didi-Huberman a partir de seu livro do fim da vida, Atlas, feito a quatro mãos com María Kodama, "entre os mais de cem artistas que reúne Atlas", ou seja, que reúne a exposição de Didi-Huberman, "não há nenhum latino-

analisado mais acima, de 1966, compreende fragmentos e notas de trabalho que remetem ao seu período em Londres e também a suas aulas no Instituto de Humanidades da Universidad Nacional del Sur), a produtividade do ensaísmo breve se encontra também no livro de Speranza, como a autora faz questão de salientar em seus "Agradecimentos": trechos do livro apareceram em eventos no México (com Néstor García Canclini em 2007), no Getty Research Institute, na Califórnia (no projeto de investigação "Surrealismo na América Latina”, 2009-2012), na Universidade de Columbia, na Universidade de Maryland, nos cursos do "Programa de artistas" da Universidade Torcuato di Tella, de Buenos Aires, e outros foram publicados em revistas como Ínsula 777 e Otra Parte, que Speranza dirige em conjunto com Marcelo Cohen. 
22. SPERANZA, Graciela. Atlas portátil de América Latina, 2012, p. 11-12. Tradução minha.

23. Além de Warburg, Erwin Panofsky foi outro nome fundamental na formação de Ciocchini. É o mesmo Panofsky que, em seu ensaio sobre a história de seu estabelecimento nos Estados Unidos, depois da fuga do nazismo, oferece um produtivo testemunho acerca das possibilidades abertas pelo "olhar estrangeiro" e pela mobilidade geográfica do pesquisador. Panofsky, nesse ensaio de 1953 sobre sua experiência de europeu recém-chegado aos Estados Unidos, "Impressões de um europeu transplantado", reflete sobre as diferenças práticas e metodológicas entre um campo e outro. Chamava-lhe a atenção o desprendimento dos profissionais estadunidenses, uma espécie de liberdade geográfica e operativa que certamente cabe também para a trajetória de Ciocchini. Escreve Panofsky: "Enquanto os historiadores de arte europeus eram condicionados a pensar em termos de fronteiras regionais e nacionais, tais limitações não existiam para os americanos", e completa: "Vista do outro lado do Atlântico, a Europa inteira, da Espanha até o leste do Mediterrâneo, fundia-se num único panorama cujos planos apareciam em intervalos apropriados e em uma luz interna”. Cf. PANOFSKY, Erwin. Significado nas artes visuais, 2001, p. 419-420. -americano. O resultado dessa retrospectiva me incomoda, não com Didi-Huberman mas comigo mesma, que, em uma vista rápida pelas obras, devo ter checado as nacionalidades dos artistas como nos controles aduaneiros" ${ }^{22}$. De certa forma, portanto, a própria concepção desse "atlas portátil” de Speranza foi marcada por uma ideia da ausência, por uma ideia de certo pertencimento compulsório ao território latino-americano.

Mais adiante, porém, Speranza especifica a questão ao abordá-lo pelo seguinte viés: o Atlas de Didi-Huberman, ao surgir concomitantemente ao projeto de Atlas de Speranza, tornou ainda mais urgente o impulso inicial que o motivou, que dizia respeito precisamente a essa invisibilidade latino-americana. Há um ponto delicado, no entanto, nessa dimensão da invisibilidade latino-americana, que surge mais como um fantasma ou um delírio persecutório latino-americano do que como prática efetiva de velamento por parte de leitores e visualizadores europeus, norte-americanos ou de onde quer que sejam. Pensando tal questão ainda mais ao extremo, e adaptando-a aos objetivos deste ensaio, é possível dizer que a invisibilidade latino-americana denunciada até certo ponto por Speranza atingiu também sua argumentação. "Até certo ponto" na medida em que tal "invisibilidade" perseguida por Speranza termina por se apresentar como uma tática paranoica, de sobreposição prévia de um problema antes que todos os elementos do cenário estejam postos ou sejam conhecidos.

Essa percepção, no entanto, talvez só se torne visível depois de todo o percurso delineado até aqui, uma vez que a hipótese é a seguinte: ao alcançar Warburg, até certo ponto, pela mediação de Georges Didi-Huberman, quando poderia tê-lo feito a partir de Héctor Ciocchini (seja por sua efetiva presença no Instituto Warburg, seja pela riqueza de sua obra e pela intensidade com que, articulando motivos arcaicos com peças artísticas contemporâneas e, no percurso, articula textos e imagens ${ }^{23}$ ), a invisibilidade latino-americana que é denunciada transforma-se, finalmente, em ponto cego no próprio texto de Speranza.

"Este livro foi um atlas muito antes da aventura sensível e intelectual do Atlas de Didi-Huberman”, escreve Speranza, tendo sido primeiro visualizado a partir da leitura de um romance de Mario Bellatín, e continua: "mas encontrou sua forma definitiva e se confiou sem reparos à potência inesgotável do princípio atlas nas salas do Reina Sofía”. Além disso, o modelo privilegiado desse novo olhar "é o Atlas Mnemosyne de Aby Warburg, um dos artefatos mais estranhos da história da arte, com o qual o historiador alemão procurou documentar visualmente todo o imaginário do Ocidente", com uma "série inacabada de painéis móveis de lâminas", que eram "montadas sobre fundos negros e logo fotografadas, na qual esperava 
expor o conglomerado de relações que observava nas imagens, as migrações de formas, motivos e gestos que atravessavam fronteiras políticas e disciplinares desde a Antiguidade até o Renascimento e inclusive até o presente" ${ }^{24}$.

Vários elementos nos solicitam até aqui, começando com a rememoração do deserto de Sonora e da Patagônia diante das imagens da exposição de Didi-Huberman, até essa potência do atlas - do "princípio atlas", como coloca Speranza - como conglomerado de "migrações de formas, motivos e gestos". Se lembrarmos o que estava em jogo na leitura que Ciocchini propõe de Saint-Exupéry, não será difícil reunir esses elementos dentro de um arco simbólico comum, que encontra seu centro gravitacional justamente na paisagem latino-americana - com um acréscimo importante: trata-se do resgate da paisagem latino-americana através de uma percepção estrangeira, deslocada tanto no tempo quanto no espaço, e uma percepção que se utiliza criticamente desse mesmo deslocamento. Pois “o que conta no Atlas Mnemosyne, finalmente, são os detalhes entrecortados da observação, portadores de singularidades históricas, e sobretudo o intervalo que cria a tela negra entre tempos e sentidos" 25 .

Mais adiante, no trecho do livro em que analisa a obra do artista visual argentino Jorge Macchi, Speranza relembra um caso paradigmático, aquele de Joaquín Torres García: "a vocação performativa do gesto", ou seja, a capacidade do gesto do artista de reestruturar o mapa do mundo a partir de sua visão, "recorda o Mapa invertido do uruguaio Joaquín Torres García, que em 1936, de volta a Montevidéu depois de quarenta anos na Europa e nos Estados Unidos, decretou a autonomia da arte da América Latina com uma simples inversão", sendo "um grito de independência da arte latino-americana”, o Mapa invertido "foi símbolo de afirmação de uma cultural local em diálogo com o mundo e manifesto visual da Escola do Sul" ${ }^{26}$. Esse resgate é importante na medida em que a intervenção de Torres García é contemporânea tanto da presença de Saint-Exupéry na América Latina quanto da publicação de seu Terra de homens (1939), livro privilegiado por Ciocchini em sua análise. Há, portanto, um substrato comum de referências que une Atlas portátil de América Latina e os ensaios de El sendero y los días ao redor de uma mesma problematização do espaço artístico latino-americano.

Para fins de conclusão, retorno ao prólogo de Speranza, ali onde se estabelece a produtividade do atlas, que é um "atlas portátil” porque "é na mobilidade real ou imaginária, na viagem ou no passeio urbano, nas migrações voluntárias e involuntárias e nas práticas e linguagens de fronteiras móveis, onde a arte e a literatura do continente parecem ter encontrado formas errantes", ou seja, formas que servem para "traduzir a
24. Ibidem, p. 14.

25. Ibidem, p. 15.

26. Ibidem, p. 52 . 
28. Ibidem, p. 17.

27. Ibidem, p. 16. experiência de um mundo conectado pelo fluxo cada vez mais nutrido no século XXI das redes globais" ${ }^{27}$. Textos e imagens, ligados numa mesma perspectiva crítica, "vão tramando na montagem respostas às perguntas pelo lugar da América Latina e da arte latino-americana, com seus próprios modos de figurar o mundo em cartografias imaginárias", e de registrar "novas experiências psicogeográficas nas cidades, abrindo-se a redes de relações flexíveis", revelando "sobrevivências na história da arte", repensando "a identidade, o território, as raízes, a língua e a pátria" 28 .

Desse modo, com a articulação e sobreposição dos projetos críticos de Ciocchini e Speranza, unidos a partir da utilização desse "princípio atlas", a reivindicação teórica do espaço latino-americano se apresenta como um work in progress que não se resolve apenas nos textos ou nas imagens, mas na confluência consciente dos dois registros. Isso porque todo território - temporal ou geográfico - está dado e composto a partir das reivindicações que o solicitam, e a concatenação progressiva dessas reivindicações que forma aquilo que se poderia chamar, eventualmente, história da literatura ou da arte, mas apenas latino-americana, mas também latino-americana. Os exercícios de ensaísmo breve analisados aqui - os de Ciocchini e Speranza, mas também aqueles que permaneceram subterrâneos, como os de Burucúa, Mario Bellatín ou Roberto Bolaño - funcionam também como indícios da produtividade dessa concatenação. Esses densos e compactos exercícios de leitura são produtivos tanto naquilo que efetivamente apresentam quanto naquilo que, em potência, deixam entrever com relação ao passado, ao presente e ao futuro daquilo que chamamos, sempre em chave crítica, América Latina. 


\section{Referências:}

AGAMBEN, Giorgio. La potenza del pensiero: saggi e conferenze.

Vicenza: Neri Pozza, 2005.

BURUCÚA, José Emilio. "Repercussões de Aby Warburg na América Latina". Trad. Alberto Martín Chillón. Revista Concinnitas. n. 21, dez. 2012. Disponível em: [http://

concinnitas.kinghost.net $/$ texto.cfm?edicao $=21 \& i d=97]$ Acesso em: $21 / 08 / 14$

Historia, arte, cultura: de Aby Warburg a Carlo Ginzburg.

Buenos Aires: Fondo de Cultura Económica, 2007.

CIOCCHINI, Héctor. El sendero y los días. Bahía Blanca:

Instituto de Humanidades, Universidad Nacional del Sur, 1973.

"La parole habitable". L'arc. Aix-en-Provence, n.22,

p. 56-63, 1963.

DIDI-HUBERMAN, Georges. "Sismographie des temps mouvants" In:_. L'image survivante: histoire de l'art et temps des fantômes selon Aby Warburg. Paris: Minuit, 2002. p. 117-125.

GINZBURG, Carlo. História noturna: decifrando o sabá. Trad.

Nilson Moulin. São Paulo: Companhia das Letras, 1991.

KLEIN, Kelvin Falcão. "O Atlas e as Passagens: rarefação do eu diante do arquivo”. Revista Confluenže. Università di Bologna, v. 5, n. 01, p. 15-25, 2013.

"Literatura e guerra aérea: poesia contemporânea

em Roberto Bolaño". Revista FronteiraZ. Pós-Graduação em

Literatura PUC-SP, n. 5, p. 02-12, março/2011.

PANOFSKY, Erwin. Significado nas artes visuais. Trad. Maria

Clara F. Kneese e J. Guinsburg. São Paulo: Perspectiva, 2001.

POPPER, Leo. Scritti di estetica. Trad. Stefano Catucci. Palermo:

Centro internazionale studi di estetica, 1997.

SPERANZA, Graciela. Atlas portátil de América Latina: arte y

ficciones errantes. Barcelona: Anagrama, 2012.

WARBURG, Aby. A renovação da Antiguidade pagã.

Contribuições científico-culturais para a história do

Renascimento europeu. Trad. Markus Hediger. Rio de Janeiro:

Contraponto, 2013. 
